\title{
Recognition of the Stimulus Suffix
}

\author{
THOMAS J. AYRES \\ Clarkson University \\ Moshe NAVEH-BENJAMIN \\ Ben-Gurion University of the Negev, Beer-Sheva, Israel
}

AND

\section{JOHN JONIDES}

The University of Michigan

\begin{abstract}
Recall of the final items in a spoken list is hindered by the presentation of a to-be-ignored item. The magnitude of this interference (the stimulus suffix effect) is reduced if the suffix is pcrccptually distinct from the other list items. Several experiments examine this effect of perceptual distinctiveness. The experiments involve later recognition of stimulus suffixes from lists presented for serial recall. Suffixes which differ from the list items tend to be recognized at least as well as list-similar suffixes. This supports the view that reduction of the suffix effect can be traced to decreased interitem interference in memory rather than to attentional selection. (C) 1986 Academic Press. Inc.
\end{abstract}

Recall of the final items in a list presented for serial recall is reduced by appending a to-be-ignored item to the end of the list (Crowder \& Morton 1969). This interference is called the stimulus suffix effect. Although this effect was believed at first to demonstrate the importance of an echoic store for recent items or auditory lists, ensuing controversy has produced alternative accounts. In this paper, several mechanisms to account for the suffix effect

This research was supported in part by National Science Foundation Grants BNS77-16887 and BNS8024512 awarded to The University of Michigan. We thank Peter Benson for his help in preparing the stimuli. Correspondence should be addressed to Thomas Ayres, Psychology Department, Colgate University, Hamilton, NY 13346; Moshe Naveh-Benjamin, Department of Behavioral Sciences, BenGurion University of the Negev, P.O. Box 653, BeerSheva 84120, Isreal; or John Jonides. Department of Psychology, University of Michigan, 330 Packard Road, Ann Arbor, MI 48104. Reprint requests should be addressed to Thomas Ayres. will be tested by focusing on the importance of the similarity of the suffix to the list items.

The magnitude of the stimulus suffix effect is a function of the perceptual similarity between the suffix and the preceding items. Final item recall is impaired more by a list-similar suffix than by a list-dissimilar one (Routh \& Frosdick, 1978). Morton, Crowder, and Prussin (1971) asserted that interference between the list items and the suffix depends on acoustic similarity and occurs in a precategorical acoustic store (PAS). This conclusion was based in part on a series of experiments apparently demonstrating that the suffix effect depends solely on the acoustic similarity of the suffix to the list, not on associative or semantic relatedness. The concept of a PAS also seemed to provide a parsimonious explanation of the serial-recall modality effect (better final-item recall in auditory than in visual list presentation) and of several 
other phenomena (Crowder, 1975; Watkins \& Watkins, 1980).

Several problems have arisen with this model, however. As a brief echoic store, the PAS fails to provide a satisfactory mechanism for recency effects in delayed recall (Baddeley \& Hitch, 1977; Penney, 1980) or for persistence of the modality effect when stimulus suffixes are included (Engle, 1974). Similarly, a store that is restricted to an echoic trace cannot be the source of suffix effects produced by auditory suffixes with tactile lists (Manning, 1977) or lip-read suffixes (Campbell \& Dodd, 1980; Spoehr \& Corin, 1978), suffix effects with self-vocalized list items and silently mouthed suffixes (Nairne \& Crowder. 1982), and suffix effects with tactual, visual, and nonverbal auditory stimuli (Foreit, 1976; Manning, 1977; Rowe \& Rowe, 1976; Shand \& Klima, 1981). Furthermore, the proposed precategorical nature of the relevant memory trace is at odds with several findings: the magnitude of the SSE is influenced by semantic variables (Routh \& Frosdick, 1978; Salter, 1975; Salter \& Colley, 1977; Salter, Springer, \& Bolton, 1976) and by the subject's categorization of the suffix as speechlike or not (Ayres, Jonides, Reitman, Egan, \& Howard, 1979; Morton \& Chambers, 1976).

Morton has acknowledged these difficulties and has suggested that PAS is neither truly precategorical nor limited to an acoustic information source. The properties of list items are presumed to define a channel, and a suffix is said to be potent for producing interference to the extent that it shares the features of the list items, including possible contextual information about the source and nature of the items (Morton, Marcus, \& Ottley, 1981). In a similar spirit, Crowder $(1978,1983)$ has proposed a metaphor in which PAS interference is seen as lateral inhibition among items represented in a multidimensional space, where such characteristics as voice quality, spatial location, and time define the relevant axes or channels (see also
Deutsch, 1972). The addition of channels to the model has the advantage of potentially accommodating results, showing that some manipulations of list/suffix acoustic similarity do not change the size of the suffix effect, presumably because some manipulations are not salient bases for channel segregation (Manning, 1984). Even the original proposal of the PAS included the possibility of attentional selection prior to cntry in the auditory storage (Morton et al., 1971). Thus current formulations of a memorial basis for the suffix effect do not require an echoic sensory store but rather place the effect within a more general cognitive framework (such as an attribute conceptualization of the memory trace (Gardiner \& Gregg, 1979).

The importance of attention as an alternative or addition to simple interference within memory has not been extensively investigated. It may be that attention contributes to the suffix effect if some selection takes place prior to item registration in memory. Subjects attempt to ignore or isolate the suffix, and their success is determined by the degree of list/suffix similarity. If the suffix is similar to the list, it may not be easily ignored; it may reach memory and interfere automatically with recent list items. A dissimilar suffix, on the other hand, could be rejected more readily and interference would be reduced.

Several researchers have concluded that both memorial and selectional processes contribute to the suffix effect (Engle, 1980; Hitch, 1975; Morton et al., 1981; Routh \& Lifschutz, 1975). This nonparsimonious overdetermination of the effect is frustrating unless it is possible to separate the contributions, as Engle has attempted by comparing the terminal (last items) and preterminal (preceding items) suffix effects. In the present experiments, we present a test of the role of selectional vs memorial mechanisms for mediating the effect of similarity in the suffix effect: that is, whether the degree of similarity between the list and the suffix affects the likelihood 
of entry of the suffix into the limited-capacity store, or instead determines the extent to which the suffix will interfere with the trace for list items after it enters the store.

The novel paradigm used in the present experiments focused on the memorial fate of the suffix in addition to the list items themselves. Each list had a different suffix; previous research has shown that the use of such nonredundant suffixes has little impact on the suffix effect (Morton et al., 1971; Penney, 1978). In the experiments to be reported, we varied the list/suffix similarity along dimensions known to affect the size of the effect. Then, following completion of the recall task for all lists, subjects completed an unexpected forced-choice recognition test for the suffixes.

A model based solely on the PAS or on similarity-sensitive interitem interference within memory allows a clear prediction. In the absence of prememorial selection, listsimilar and list-dissimilar suffixes should be registered in memory equally well. Thus we would expect no differences in later recognition scores between the two types of suffix.

Consider the prememorial selection stage. A suffix which is dissimilar from the list items is effectively segregated or excluded prior to registration in memory, thereby reducing its interference with list items. According to Kahneman and Henik (1977), the segregated suffix does not share the processing resources applied to the list; in a limited-capacity system, this leaves fewer resources available for processing the suffix. Thus, the dissimilar suffix itself would be only poorly stored. Given that recognition tests are sensitive to the amount of effort and attention devoted to items when they are presented (NavehBenjamin \& Jonides, 1984a, 1984b), later recognition accuracy for a stimulus suffix ought to be directly related to the similarity of the suffix and the list.

We conducted a series of preliminary experiments involving immediate serial recall of 35 auditorily presented lists of seven monosyllabic nouns and a nonredundant suffix at the end of each list, followed afterward by a surprise four-alternative recognition test for the suffixes. It was assumed that following a series of practice trials the subjects would easily learn to distinguish list items (drawn from a fixed pool of 12 tokens) and the nonredundant suffixes; the absence of intrusions of the suffixes into list recall supported this assumption.

Spatial location of the suffix was varied in the first two studies (by playing the suffix through a loudspeaker placed either close to the one used for the list items or far away, or by presenting the suffix in the same or opposite headphone). In the third study voice quality was manipulated by reading the list items in a male voice and the suffixes in either a male or a female voice. Since we were primarily interested in the contrast between the two types of suffixes rather than in the absolute magnitude of suffix effects, no control condition (lists without suffixes) was included in any of the experiments reported here.

We operationally defined the stimulus suffix effect as the difference in last-item recall (seventh position) between the listsimilar and list-dissimilar suffix conditions. Although the suffix effect has also been defined in other ways, an emphasis on final position is most consistent with the PAS model (see Crowder, 1978) which is being tested here: effects at early positions are thought to depend more on some other mechanism (Engle, 1974).

In all of these experiments, recall of items in the seventh position of the lists was significantly poorer with list-similar than with list-dissimilar suffixes (by 11,11 , and $20 \%$ in the three studies). Later recognition of the list-dissimilar suffixes was consistently better than for the list-similar suffixes (by 4,2 , and $5 \%$ ), but the differences were not statistically significant. Although it seemed clear that list-similar suffixes did not have the recognition advan- 
tage predicted by the attentional hypothesis, the unexpected finding of a slight advantage for list-dissimilar suffixes prompted further testing. To this end, an attempt was made in the following study to increase the perceptual difference between the lists and the dissimilar suffixes by manipulating both voice quality and number of syllables. It was hoped that differences in recognition between the two types of suffix would be accentuated if the size of the stimulus suffix effect were increased.

\section{EXPERIMENT 1}

The number of syllables in the suffixes was varied by using nouns having either one or two syllables, and voice quality was varied by having either a malc or a female voice for suffixes appended to male-voice lists. To ensure that differences in recognition could not be attributed just to the effects of voice quality or syllable number alone, a tape was prepared in which the two-syllable, female-voice words were alternated (one per second) with the one-syllable, male-voice words. Twenty-six subjects who did not take part in any other experiments listened to this tape; afterward, they were asked to try to recall as many items as possible, and then a recognition test was given as well. Recall and recognition were both better than chance, and no differences were found between the two types of suffix.

\section{Method}

Subjects. Forty undergraduate students (aged 18-22) participated in return for credit in an introductory psychology course at Clarkson University; approximately equal numbers of males and females were assigned to each condition.

Materials. Forty-five lists of seven words each were prepared by drawing without replacement from a set of 12 monosyllabic nouns (Ayres et al., 1979). Suffixes were one- or two-syllable nouns with high usage frequency (>100/million) (Kucera \&
Frances, 1967) which were not obviously related semantically or acoustically to the list items. Each two-syllable suffix had the accent on the first syllable. Lists and suffixes were recorded by two practiced readers at the rate of two items per second, using a metronome pulse provided via headphones to time the reading; each list was recorded enough times to ensure a final version which sounded smooth and flawless. List items were read by a male voice, and suffixes were read by either the same male voice (for list-similar, one-syllable suffixes) or by a female voice (for listdissimilar, two-syllable suffixes). A 0.2 -s warning tone preceded each list by $1 \mathrm{~s}$. Two versions of the tape were prepared. In one condition, list-similar suffixes were used with lists 1-5 and 11-28; for the other condition, list-similar suffixes were used with lists $1-5$ and 29-45. All other lists had listdissimilar suffixes.

The recognition test sheet had 24 rows of four words; each row contained one of the suffixes from trials $17-40$ (in random order) along with three distractors having the same number of syllables and the same usage frequency as the correct suffix.

Procedure. Lists were presented via loudspeaker to the groups. Subjects were instructed to ignore the suffixes and to recall the lists in order immediately after presentation using a response sheet having seven blanks per line. Lists $1-10$ were described as practice lists to familiarize the subjects with the stimuli and the two types of suffixes which would be used. The remaining 35 lists were then presented, stopping after list 28 to warn of the change in suffix type. Fourteen subjects heard one of the two recorded versions, and 26 heard the other version. Results for lists 1-16 were discarded as practice, as were results from lists 41-45 which were presented only to act as a buffer for long-term recency effects (Rundus, 1980). Lists 17-28 were scorcd to examine the suffix effect for one type of suffix, and 29-40 for the other 
type. An item was scored as correct only if it appeared in the correct position in the list.

\section{Results}

There were no significant effects of presentation order or group. Figure 1 shows the percentage of correct responses for each serial position in each suffix condition. The list-similar suffixes produced lower seventh-item recall than did the listdissimilar suffix $(29 \%$ vs $56 \% ; t(39)=8.50$, $p<.001$ ).

Recognition for the list-dissimilar suffixes was $41.7 \%$, whereas for list-similar suffixes it was only $29.4 \%$, not better than chance. The difference between conditions was reliable $(t(39)=4.10, p<.01)$.

\section{Discussion}

The results of this experiment agreed with the pilot studies insofar as no recognition advantage was found for list-similar suffixes. Since the prediction of the attention model is thus disconfirmed, it appears that that model can be rejected-the improvement in final-item recall that comes from making the suffix distinct from the list is not a sign that a list-dissimilar suffix has been effectively ignored and rejected from processing.

On the contrary, the large difference in

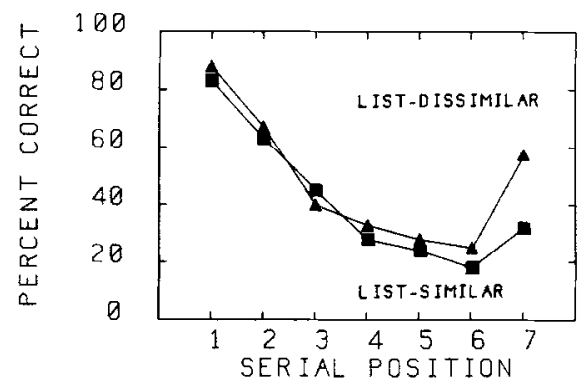

FIG. 1. Percentage of correct recall in each serial position for lists with the suffix spoken by the same voice as the list and with the same number of syllables in suffix and list items (monosyllabic, same voice), and spoken by a different voice with suffix items having greater syllable length than list items (disyllabic, different voice). seventh-position recall (27\%) was accompanied by a large and significant recognition advantage for list-dissimilar suffixes. This finding bears at least a superficial resemblance to the Von Restorff effect, in which recall for a given item is improved if the item possesses novelty by being distinct from the rest of the list (Wallace, 1965). Suppose that effect were operating in the experiment just described: then recognition may have been enhanced for the list-dissimilar suffixes, which were the only female-voice and two-syllable items, solely because of their relative distinctness. In the following experiment, we attempted to reduce the possible effects of novelty or distinctness of the list-dissimilar suffixes by counterbalancing the conditions so that subjects heard all combinations of list and suffix type. Items and suffixes were either monosyllabic nouns spoken by a male voice or disyllabic nouns spoken by a female voice.

\section{EXPERIMENT 2}

\section{Method}

Subjects. Thirty-six undergraduate students were recruited from a psychology subject pool at the University of Michigan and were paid for participation.

Materials. Tape recordings of 15 lists were prepared for each of four conditions. In the first condition, items in the sevenitem list were drawn from the set of monosyllabic nouns used in the previous studies, and were spoken by a male voice. The nonredundant suffixes were drawn from the set of monosyllabic nouns used in Experiment 1 , and were spoken by the same male voice. In the second condition, items were drawn from a set of 12 disyllabic nouns having the accent on the first syllable, and suffixes were drawn from the set of disyllabic nouns used previously; all were spoken by the same female voice. These two conditions both preserved list/ suffix similarity. The remaining two conditions employed list-dissimilar suffixes by 
combining the male-spoken monosyllabic items with female-spoken disyllabic suffixes and vice versa. Only lists $4-15$ in each condition were to be scored; the first three lists provided practice and familiarity with the condition.

In addition, four practice tapes of five lists each were prepared corresponding to the four conditions.

The forced-choice recognition test sheet had 48 rows of four words. In each row, one word was a suffix from the scored trials of the recall lists, and the other words were distractors with the same number of syllables. Average word frequency was approximately the same for suffixes and distractors. Suffixes from the four conditions appeared in random order on the recognition test.

Procedure. Recordings were presented by loudspeaker to individuals or small groups (two-four subjects). Each subject heard all four recordings; order was varied across subjects (Latin square). A practice tape with the same list and suffix characteristics as the first condition to be used was played at the beginning of the session. The surprise suffix recognition test was given at the end of the 65 recall lists.

\section{Results}

There were no significant effects of presentation order. Performance on malevoiced list-similar suffix trials did not differ systematically from that on female-voiced list-similar suffix trials, nor did results for the two types of list-dissimilar trials differ from one another. Therefore data were pooled across these variables. Figure 2 shows percentage of correct recall for each serial position in list-similar and list-dissimilar suffix trials. Recall of items at position 7 was significantly better with list-dissimilar than with list-similar suffixes $(61 \%$ vs $50 \% ; t(35)=5.31, p<.001)$.

The difference in recognition between list-similar and list-dissimilar suffixes was not significant $(37.3 \%$ vs $35.7 \%$, respectively; $t(35)=0.41, \mathrm{~ns})$.

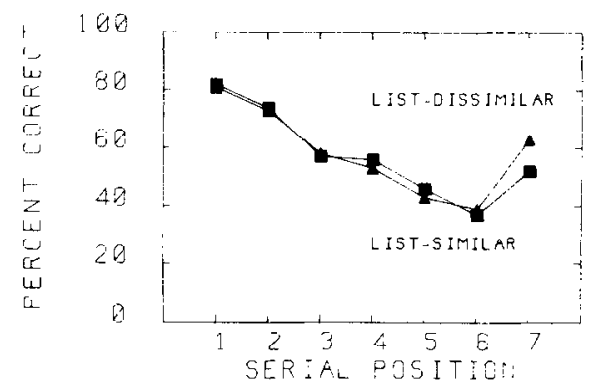

FIG. 2. Percentage of correct recall in each serial position for lists having suffixes matching in voicc and syllable length (similar) or differing along both dimensions (dissimilar).

\section{Discussion}

Once again list-similar suffixes produced significantly poorer final-item recall than did list-dissimilar suffixes (the usual stimulus suffix effect) without any significant recognition advantage for the list-similar suffixes. In this case, however, with the counterbalancing of conditions to expose subjects to all combinations of list and suffix characteristics, the recognition advantage found earlier for list-dissimilar suffixes was absent. Thus the major finding of this series of experiments was that later recognition of a suffix is not necessarily related to its similarity to the preceding list or to how effectively it interfered with finalitem recall.

\section{General Discussion}

One thing seems certain at this point: a suffix which is perceptually distinct from the list is later recognized at least as well as a list-similar suffix. Therefore the mechanism responsible for improving final-item recall when the suffix is perceptually distinct from the list cannot be an attentional selection process that excludes such a suffix and prevents memorial registration. These results are consistent with the hypothesis that all suffixes enter memory and have equal opportunity for later recognition, while the degree of interference between a suffix and the last item in the list is a function of their similarity. 
This gives us some insight into what takes place in a suffix experiment. We ask our subjects to "ignore" the sound or item at the end of each list, but in fact they probably do not ignore it in the same way that the unattended ear in a shadowing experiment is ignored. The ignoring is more likely to occur during retrieval, when subjects attempt to recall the list items but leave out the suffix.

Given that a list-dissimilar suffix is not actually ignored, what mechanism if any might underlie the suffix effect in addition to intramemorial interference? Actually there are several contenders available. A list-dissimilar suffix could be shunted (whether automatically or deliberately is an unresolved question) into a different channel from the list items (Crowder, 1983); this would reduce interference between list items and suffix but would not necessarily affect later recognition of the suffix. A related possibility is that a list-dissimilar suffix may be partitioned into a separate group in the course of pattern perception (Kahneman, 1973; Kahneman \& Henik, 1977), thereby reducing list-suffix interference in memory or preserving the temporal distinctiveness of the final items (Frankish \& Turner, 1984; Gardiner, 1983; Manning \& Turner, 1984). The common thread in these proposals, consistent with the present findings, is that the control processes operating in a suffix experiment may separate the suffix from the list, but they do not actually exclude it.

\section{REFERENCES}

Ayres, T. J., Jonides, J., Reitman, J. S., Egan, J. C., \& HowaRD, D. A. (1979). Differing suffix effects for the same physical suffix. Journal of Experimental Psychology: Human Learning and Momory, 5, 315 -321.

Baddeley, A. D., \& Hitch, G. (1977). Recency reexamined. In $S$. Dornic (Ed.), Attention and performance (Vol. 6). New York: Erlbaum.

Campbell, R., \& Dodd, B. (1980). Hearing by eye. Quarterly Journal of Experimental Psychology, 32, 85-99.

Crowder, R. G. (1975). Inferential problems in echoic memory. In P. M. A. Rabbitt \& S. Dornic
(Eds.), Attention and performance (Vol. 5). New York: Academic Press.

CROwder, R. G. (1978). Mechanisms of auditory backward masking in the stimulus suffix effect. Psychological Review, 85, 502-524.

Crowder, R. G. (1983). The purity of auditory memory. Philosophical Transactions of the Roval Society of London B, 302, 251-265.

Crowder, R. G., \& Morton, J. (1969). Precategorical acoustic storage (PAS). Perception and Psychophysics, 5, 365-373.

DEUTSCH, D. (1972). Mapping of interactions in the pitch memory store. Science, 175, 1020-1022.

ENGLE, R. W. (1974). The modality effect: Is precategorical acoustic storage responsible? Journal of Experimental Psychology, 102, 824-829.

ENGLE, R. W. (1980). The suffix effect: How many positions are involved? Memory \& Cognition. 8(3), 247-252.

FOREIT, K. G. (1976). Short-lived auditory memory for pitch. Perception and Psychophysics, 19, $368-370$.

Frankish, C., \& Turner, J. (1984). Delayed suffix effect at very short delays. Journal of Experimental Psychology: Learning, Memory and Cognition, 10(4), 767-777.

Gardiner, J. M. (1983). On recency and echoic memory. Philosophical Transactions of the Royal Society of London B, 302, 267-282.

Gardiner, J. M.. \& GregG, V. H. (1979). When auditory memory is not overwritten. Journal of Verbal Learning and Verbal Behavior. 18, $705-719$.

HITCH, G. J. (1975). The role of attention in visual and auditory suffix effects. Memory \& Cognition, $3(5), 501-505$.

Kahneman, D. (1973). Attention and effort. Englewood Cliffs, NJ: Prentice-Hall.

KAHNEMAN, D. \& HENIK, A. (1977). Effects of visual grouping on immediate recall and selective attention. In S. Dornic (Ed.), Attention and performance (Vol. 6). New York: Erlbaum.

KucEra, H., \& Francis, W. (1967). Computational analysis of present-day American English. Providence, RI: Brown Univ. Press.

ManNing, S. K. (1977). Suffix effects on non-verbal tactual, visual, and auditory sequences. Paper presented at the meeting of the Psychonomic Society, Washington DC.

MANNING, S. K. (1984). Effects of difficulty variables and type of suffix on serial recall. American Journal of Psychology, 97(1), 71-87.

Manning, S. K., \& Turner, J. S. (1984). Recency and end-of-sequence suffix effects are not always linked. American Journal of Psychology, 97(3), 407-417.

Morton, J., \& Chambers, S. M. (1976). Some evidence for "speech" as an acoustic feature. British Journal of Psychology, 67, 31-45. 
Morton, J., Crowder, R. G., \& Prussin, H. (1971). Experiments with the stimulus suffix effect. Journal of Experimental Psychology Monograph, 91, $169-190$

Morton, J., Marcus, S. M., \& OtTley, P. (1981). The acoustic correlates of "speechlike:" A use of the suffix effect. Journal of Experimental Psychology: General, 110, 568-593.

NaIRNe, J. S., \& Crowder, R. G. (1982). On the locus of the stimulus suffix effect. Memory-Cognition, 10(4), 350-357.

Naveh-Benjamin, M., \& Jonides, J. (1984a). Maintenance rehearsal: A two-component analysis. Joumal of Experimental Psychology: Learning. Memory and Cognition, 10(3), 369-385.

NAVeh-BeNJAMin, M., \& JoNides, J. (1984b). Cognitive load and maintenance rehearsal. Journal of Verbal Learning and Verbal Behavior, 23, 494-507.

Penney, C. G. (1978). Suffix effects in lists of temporally grouped words. Quarterly Journal of $E x$ perimental Psychology, 30, 235-250.

PenNey, C. G. (1980). Order of report in bisensory short-term memory. Canadian Journal of Psvchology, 34, 190-195.

Routh, D. A., \& Frosdick, R. M. (1978). The basis and implications of the restoration of a recency effect in immediate serial recall. Quarterly Journal of Experimental Psychology, 30, 201-220.

Routh, D. A., \& Lifschutz, A. J. (1975). An asymmetrical effect of similarity in the attenuation of stimulus suffix interference. Journal of Verbal Learning and Verbal Behavior, 14, 95-104.
Rowe, E. J., \& Rowe, W. G. (1976). Stimulus suffix effects with speech and nonspeech sounds. Memory \& Cognition, 4, 128-131.

Rundus, D. (1980). Maintenance rehearsal and longterm recency. Memory \& Cognition, 8, 226-230.

SALTER, D. (1975). Maintaining recency despite a stimulus suffix. Quarterly Journal of Experimental Psychology, 27, 433-443.

Salter. D.. \& Colley. J. G. (1977). The stimulus suffix: A paradoxical effect. Memory \& Cognition, 5, 257-262.

SAlter, D., Springer, G. . \& Bolton, L. (1976). Semantic coding versus the stimulus suffix. British Journal of Psychology, 67, 339-351.

Shand, M. A., \& KLIma, E. S. (1981). Nonauditory suffix effects in cogenitally deaf signers of American Sign Language. Journal of Experimental Psychology: Human Learning and Memory. 7, 464-474.

SPOEHR, K. T, \& CORIN, W. J. (1978). The stimulus suffix effect as a memory coding phenomenon. Memory \& Cognition, 6, 583-589.

WALLACE, W. P. (1965). Review of the historical, empirical, and theoretical status of the von Restorff phenomenon. Psychological Bulletin, 63, 410-424.

WatKIns, O. C.. \& WatKIns, M. J. (1980). The modality effect and echoic persistence. Journal of Experimental Psychology: General, 109, 251-278.

(Received December 3, 1985)

(Revision received February 26, 1986) 